\title{
Gender in Management: An Investigation In The Pakistani Corporate World
}

\author{
Mustaghis-ur-Rahman \\ \& \\ Aliya Ahmed \\ Department of Management Science \& Social Sciences \\ SZABIST University, Karachi
}

\begin{abstract}
John Gray presents interesting metaphor for men and women in his best seller title "Men are from Mars and Women are from Venus" as men are warrior; protector of fields and territory while women are the symbols of love, beauty and fertility in a society. If summed up the characteristics of men and women in single word for each, explained by Gray, most probably the men are 'tuff' and women are 'fragile'. Are they really so? The claim of Gray can not be out rightly rejected. Although most of the researches in the field of 'gender and management' did not endorse the Gray's analogy but accepted a few differences in the management and leaderships styles of men and women at the work place. In Pakistan too, gender equality or inequality is being debated like anywhere in the world. Pakistani organizations are predominantly managed by men. Few women can be seen at the top slot of management in the Pakistani corporate organizations. It is generally perceived that management is a masculine role, though management role is not a single role rather management roles are further classified into various sub roles, whereas some are perceived masculine and others are perceived as feminine roles. Being an active part of the corporate world, the researchers have observed differences in the managerial styles between men and women and wanted to find out through scientific method whether in Pakistani corporate culture, is management still associated with men only or its sub roles are more/less associated with men and women; both?
\end{abstract}

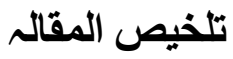

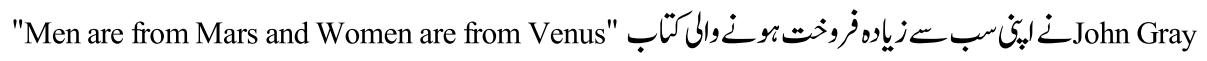

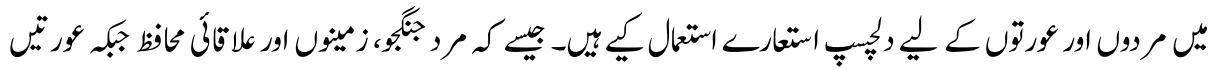

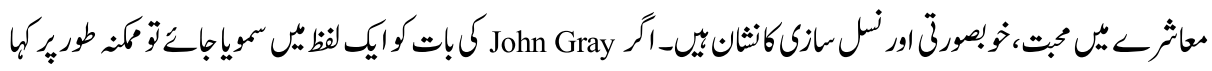

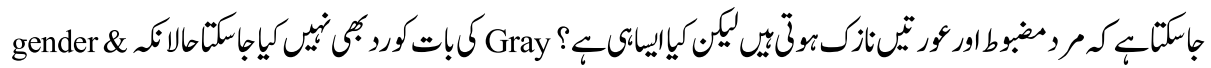
Granagement

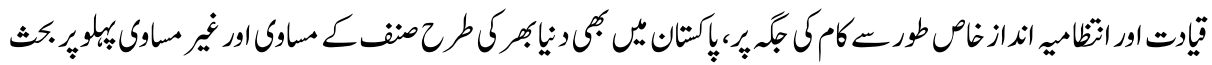

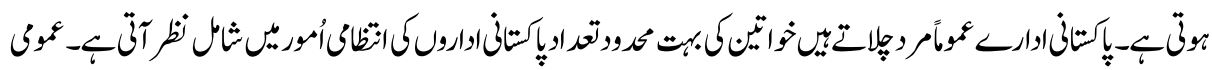

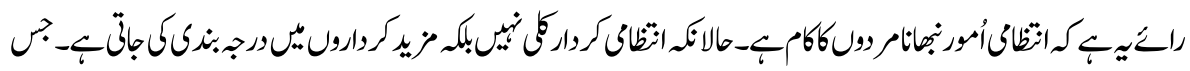




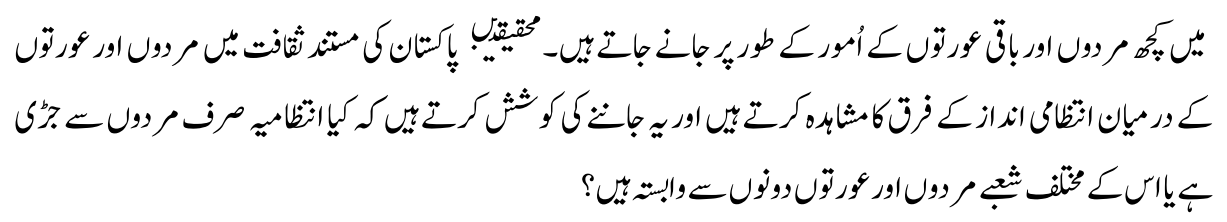

\section{Introduction}

Pakistani organizations are predominantly managed by men. It is generally perceived that 'management' is a masculine role, although if we go into the detail of the management roles, we find management consists of several sub roles where some are perceived masculine and others are feminine roles. Accordingly, the management roles or sub roles have also been labeled as gendered roles. The term 'gender' differentiates the socially constructed roles from the biologically determined aspects of being male and female. Also, gender refers to the society's expectations to perceive our roles as women and men in a society under the prevailing social compulsions. In fact, society is not organized on the basis of biological differences as increasing number of women in the industrialized societies are employed in various economic activities; from manual worker to the top positions in the global companies. In those countries, the divisions between the gender roles are changing.

Making base of the above mentioned common gender knowledge; this paper digs deeper the $14 \mathrm{sub}$ roles identified by the Gary Yukl. To investigate the general perception of management sub roles as masculine or feminine in nature in the Pakistani corporate organizations, a sample of 13 multinational organizations selected randomly out of total 362 Karachi based organizations through the inferential statistics. For the purpose a hypothesis was developed to test their validity through probability distribution tables

\section{Management Sub Roles and Gender}

The subject 'Management' has been defined and further explained by various scholars in order to get maximum benefit of it. Follett (Cited in Graham 1995) says management is "the art of getting things done through people" Koontz (1993) broadens the scope of management by defining it as "Management is the process of designing and maintaining an environment in which individuals, working together in groups, efficiently accomplish selected aims". Whereas Fayol (Cited in Koontz 1993) is of the view "Management is to forecast, to plan, to organize, to coordinate and to control". The above mentioned definitions' basic theme revolves around the three important factors: goal accomplishment; efficient working; and functionalities of management. Management has also been tried to understand from the 'managerial roles' perspective. Mintzberg in 1973, introduced the concept of "managerial roles". He is of the view that roles associated with the management of organizations are like the roles played by the artists on the stage. Managers perform various roles as per their role title (Mintzberg; 1980). For example, 
organizing implies liaison and disturbance handler role; planning involves entrepreneurial thinking and conceptualization roles; while motivating role is associated with the leadership role; similarly controlling is based on the roles of monitoring and problem shooting. Besides, managerial role is to interact with people -subordinates, superiors and clients (Koontz 1993). The managerial roles by Mintzberg were the impetus for a management scholar Gary Yukl who further elaborated on management roles and extended them to fourteen managerial roles under the term 'managerial behaviors'. For this particular study Gary Yukl's managerial roles were taken as it is more specific and could cater better to our objectives in comparison to the roles defined by Mintzberg as they are more general in nature. Yukl described the taxonomy as follows. "This taxonomy is based primarily on factor analysis, but judgmental classification and theoretical deduction were also used to identify categories that maintain continuity with earlier taxonomies and research. The behavior categories are generic enough to be widely applicable to different kinds of managers, but specific enough to relate to the unique situational demands and constraints confronted by an individual manager"(Yukul 2002) The 14 management sub roles identified by Yukul are: "Planning and organizing, Problem-solving, Clarifying roles and objectives, Informing, Monitoring, Motivating and inspiring, Consulting, Delegating, Supporting, Developing and mentoring, Managing conflict and team-building, Networking, Recognizing, Rewarding”(Yukul 2002)

\section{Gender and Management}

Gender Management is also a term used in management studies. While women and men both undertake different activities and produce different goods and services, they are mutually dependent on each other. However, this allocation of tasks and values varies greatly from one organizational culture to another, and at different time periods. This is an indication that the gender role itself is a cultural construction of organization affected by the form of the respective society and its economic and political set-up. A brief discussion is undertaken on the women participation in Pakistani corporate world and also on the challenges and opportunities of gender diversity worldwide in the subsequent subheadings.

\section{Women Participation in Corporate Organizations in Pakistan}

Women are $47.3 \%$ of the total population of Pakistan, out of these $20.14 \%$ is employed in the formal sector (Bureau of Statistics 2005-2006). And even less than $1 \%$ national and multinational enterprises are owned by women. Pakistan ranks high in gender inequality compared internationally (Salman \& Rahman 2008). Though, in the last couple of years, some indicators relating to women's status have improved, several have remained static, and some has further deteriorated. The reasons for disparities in men and women status in this country include social biases, cultural taboos, inadequate policies, lack of political will and legislations for the gender sensitized development. 
Despite many odds, more women are making their ways in the corporate world, especially, in those jobs which were previously known as men's profession. It is true that until now highly-qualified women are still heavily concentrated in teaching and medicine. This trend has been influenced by women's own capability and a comparatively liberal government policy in the last two decades. Also shrinking opportunities in the public educational and public health system has negatively affected women's career options in the traditional fields of employment. Only 25 years ago no women were employed in banks, now a days many banks have female employees. The 'First Women's Bank' which was established in 1990 made possible the employment of women into banking at large scale. Similarly, women have entered disciplines like 'finance' and 'management', and they work in higher administrative positions in the government and private sector. More and more women are choosing business management, journalism, law as an academic discipline and working as professionals after their studies. We have examples of Ameena Sayied of Oxford University Press or Musharraf Hai of CitiBank, Akram Khatoon of First Women Bank who have reached to highest positions in the hierarchy of organizations they were working with.

\section{Trends Issues and Challenges in Managerial Diversity}

Writers like Christine de Pisan in the 15th century and feminists like Mary Wollstonecraft, Elizabeth Cady Stanton and Minna Canth in the 18th and 19th century also have contributed a lot in terms of special characteristics of women in management. In the contemporary works, Hilkka Pietila, Hazel Henderson, Devaki Jain and Peggy Antrobus have significant contributions on the subject of women in management (Partnership way 2006). A number of men writers have also significant contributions in highlighting the issue of the gender equality and equity at the work place as Mill, Marx, Engels, and Fourier. Fourier, over a century ago observed that "the degree of the emancipation of women is an index to the degree of society's emancipation" (Kochan et al, 2003). But, generally, the discussions on women development or the gender equality has hardly been given a serious thought in the power corridors. This is only in the past few years this discussion has been entering the realm of best-selling books on the future of business and economics, such as "Reinventing the Corporation" (John \& Aburdene 1988).

Several studies have been under taken in the northern world to see whether diversity at workplace is beneficial or not. The study 'Makes and Breaks of Diversity Initiatives' found those successful initiatives that includes diversity increase organizational effectiveness and introduce new approaches in management (Janine, Matton and Christine 2004). Another study 'Diversity Practices that Works' found that diversity practices at the work place increased productivity by $18 \%$. The findings imply that diversity in the organization in management increases productivity under the supervision of an able leadership and in the diversity sensitized environment (National Urban League 
- USA 2004). A mega research on 'Connecting Corporate Performance and Gender Diversity' examined 353 'Fortune 500' companies, which concluded in the following words "the group of companies with the highest representation of women on their top management teams experienced better financial performance than the group with the lowest women's representation: that is, $35 \%$ higher return on equity and $34 \%$ higher total return to shareholders" (Catalyst Women 2003).

\section{Data Analysis and Presentation}

Below mentioned hypothesis, comprising the variables of 14 subs roles in management given by Yukul, was tested by probability distribution technique. The results of the test are presented in Table 1.

H1: The perception about 14 management sub roles identified by Yukul are both; masculine and feminine.

H0: The perception about 14 management sub roles identified by Yukul are masculine

Table 1

Probability Distribution of Sub Roles

\begin{tabular}{|l|c|c|c|c|}
\hline \multirow{2}{*}{ Sub Role } & \multicolumn{4}{|c|}{ Probabilities } \\
\cline { 2 - 5 } & Masculine & Feminine & Both & Total \\
\hline Planning and Organizing & 0.187 & 0.112 & 0.701 & 1.000 \\
\hline Problem - Solving & 0.327 & 0.093 & 0.579 & 1.000 \\
\hline Clarifying Role and Objective & 0.243 & 0.150 & 0.607 & 1.000 \\
\hline Informing & 0.140 & 0.271 & 0.589 & 1.000 \\
\hline Monitoring & 0.308 & 0.103 & 0.589 & 1.000 \\
\hline Motivating and Inspiring & 0.187 & 0.159 & 0.654 & 1.000 \\
\hline Consulting & 0.140 & 0.178 & 0.682 & 1.000 \\
\hline Delegating & 0.280 & 0.150 & 0.570 & 1.000 \\
\hline Supporting & 0.168 & 0.206 & 0.626 & 1.000 \\
\hline Developing and Mentoring & 0.252 & 0.093 & 0.654 & 1.000 \\
\hline Managing Conflict and Team-Building & 0.327 & 0.084 & 0.589 & 1.000 \\
\hline Networking & 0.234 & 0.103 & 0.664 & 1.000 \\
\hline Recognizing & 0.084 & 0.196 & 0.720 & 1.000 \\
\hline Rewarding & 0.215 & 0.093 & 0.692 & 1.000 \\
\hline
\end{tabular}

The probability distribution for each sub role suggests that our null hypothesis does not stand true and the alternate hypothesis is accepted as the results for the sub role 'Planning \& Organizing' shows that probability of occurrence is 0.701 for 'both', 0.112 for 
feminine and 0.187 for masculine thus resulting that 'Planning \& Organizing' is a role perceived most commonly as effective for both. The results for the sub role 'Problem Solving' shows that probability of occurrence is 0.579 for both, 0.093 for feminine and 0.327 for masculine thus resulting that 'Problem Solving' is a role perceived most commonly as effective for both, however the probability of occurrence for Males is also quite high so although the assumption is not correct but still we can see that a high inclination could be seen towards Males. The results for the sub role 'Clarifying Role and Objective' shows that 0.60 probability of occurrence is towards sub role 'both', 0.15 for female and 0.243 for masculine thus resulting that 'Clarifying Role and Objective' is a role perceived most commonly as effective for both, however a large proportion of sample has also responded it to be more effective for males.

The results for the sub role 'Informing' shows that 0.589 probability of occurrence is for sub role 'both', 0.271 for female and 0.14 for male thus resulting that 'informing' is a role perceived most commonly as effective for both, however a large proportion of sample has also responded it to be more effective for females. The results for the sub role 'Monitoring' shows that probability of occurrence is 0.589 for 'both', 0.103 for females and 0.308 for males thus resulting that "Monitoring" is a role perceived most commonly as effective for both, however the probability for males is also very high and could not be neglected so although the assumption does not stand true for this sub role however the inclination towards males for this sub role is also very prominent.

The results for the sub role 'Motivating \& Inspiring' shows that probability of occurrence is 0.654 for 'both', 0.159 for female and 0.187 for males thus resulting that 'Motivating $\&$ Inspiring' is a role perceived most commonly as effective for both. The results for the sub role 'Consulting' shows that probability of occurrence is 0.682 for 'both", 0.178 for females and 0.140 for males thus resulting that 'Consulting is a role perceived most commonly as effective for both. The results for the sub role 'Delegating' shows that probability of occurrence is 0.570 for 'both', 0.15 for female and 0.28 for male thus resulting that 'Delegating' is a role perceived most commonly as effective for both, however again here it can be noticed that probability of occurrence is quite high for Males.

The results for the sub role 'Supporting' shows that probability of occurrence is 0.626 for 'both', 0.206 for females and 0.168 for males thus resulting that 'Supporting' is a role perceived most commonly as effective for both. The results for the sub role 'Developing \& Mentoring' shows that probability of occurrence is 0.654 for 'both", 0.093 for females and 0.252 for males thus resulting that 'Delegating' is a role perceived most commonly as effective for both, however the probability of occurrence for Males is again on a higher side reflecting that a large proportion of sample perceive this sub role as masculine in nature. The results for the sub role 'Managing Conflict \& Team Building' shows that probability of occurrence is 0.589 for 'both', 0.084 for female and 0.327 for male thus 
resulting that 'Managing Conflict \& Team Building' is a role perceived most commonly as effective for both, however here again the probability of occurrence for males is high and we can infer that a large number of respondents had the perception that this sub role is more for Males.

The results for the sub role 'Networking' shows that probability of occurrence is 0.664 for 'both', 0.103 for female and 0.234 for males thus resulting that 'Networking is a role perceived most commonly as effective for both, however still a trend is also towards Masculine nature. The results for the sub role 'Recognizing' shows that probability of occurrence is 0.720 for 'both', 0.196 for female and 0.084 for males thus resulting that 'Recognizing' is a role perceived most commonly as effective for both, however still a tendency could also be seen towards Feminine type. The results for the sub role 'Rewarding' shows that probability of occurrence is 0.692 for 'both', 0.093 for female and 0.215 for male thus resulting that "Rewarding" is a role perceived most commonly as effective for both, however since here again we can observe that the probability of occurrence is also high for males so once can see that a large proportion of the respondents perceive this sub role as masculine in nature.

\section{Results and Interpretation}

The empirically tested results reveal that 14 management sub roles have characteristics of masculine and feminine; both. This research refutes the general perception of 'Management roles' as masculine rather it reveals that management roles are suitable for males and females both. The individual analysis of each variable finds that some of the sub-roles, such as: 'Planning and Organizing', 'Problem Solving', 'Clarifying Roles and Objectives', 'Monitoring', 'Motivating and Inspiring', 'Delegating', 'Developing and Mentoring', 'Managing Conflict and Team-Building', 'Networking', and 'Rewarding', can be performed better than women. While women can perform better than men in the roles like: 'Informing', 'Consulting', 'Supporting', and 'Recognizing'. Since this research was to investigate whether the management roles are masculine or both (masculine and feminine) in nature, our interpretation is that management roles are both masculine and feminine as the result for 'both' out numbered with significant number of observations by the respondents in comparison to the observations for masculine and feminine separately.

\section{Conclusion and Recommendations}

Pakistan is among developing countries and women participation in the economic activities is still low compared to even many developing nations. However, the results of this research reflect the open mindedness of men for female peers in the work environment. The reasons for having confidence in the abilities of women could be that now women are entering into all professional fields in Pakistan and they are making their 
positions, through slowly. So people are accepting women as capable managers in the corporate world. Also media is highlighting the contribution of women in every field and the positive perception of people is reflecting the image which has been created for women by media. Another important reason for such liberal thinking could also be that the respondents of this research belong to the multinational and well organized Pakistani organizations so the sample represented the educated cadre of the society which is far more modern in their approach as compared to masses living here.

In the lights of the results, researches recommend, in Pakistani corporate organizations, gender biased approach at workplace should be discouraged through a written policy as there is no basis of discrimination against any gender or sex at the work place. Men and women equity and equality concepts should also be incorporated in the training manuals, designed for future Managers and professionals. Pakistani women should be given more exposure and career orientation during their academic life so that their participation increases in the corporate sector. For all professional fields both genders should be given equal opportunity and stereotyping of professions should be avoided.

\section{Future Areas of Research}

For future research areas could be to find out the reason that though the mindset is favorable in Pakistan for women managers, why is the case that we don't have equal number of representation of women in all sectors and organizational hierarchy. Also what are the factors create obstacles in the upward mobility of women in the organizational hierarchy? Is this the glass ceiling which stops women in the advancement of their career? If yes than what are the factors that construct that glass ceiling. Similarly it could also be explored that do people really analyze these roles in terms of their effectiveness related to gender or is it the social influence which shape their opinion.

\section{Reference}

Albert J. M. and Peta T. (1992) Gendering Organizational Theory, Sage Publications, Thousand Oaks, CA.,

Bureau of Statistics, Govt. of Pakistan 2006, Lobour Force Survey, p-36

Eagly, A. H., Makhijani, M. G., \& Klonsky, B. G. (1992) Gender and The Evaluation of Leaders: A Meta-Analysis, Psychological Bulletin, pp 3- 22.

Graham , P (ed) (1995) Prophet of Management, Beard Books, London.

Janine, N. Matton and Christine M. (2004) Makes \& Breaks of Diversity Initiatives, Research Report, John Hopkins, USA 
John, M. (1988) Reinventing the Corporation, McGraw Hill, London

Kochan, T, Bezrukova, K. Ely, R, Jackson, S. Joshi, A. Jehn, K.Leonard, J. Levine, D. Thomas, D. 2003, The Effects of Diversity on Business Performance: Report of the Diversity Research Network (unpublished)

Koontz, H (1993) Management: A Global Perspective, McGraw Hill, Singapore

Mintzberg, H. (1980) The Nature of Managerial Work, N.J: Prentice-Hall, New York

National Urban League - USA (2004) Diversity Practices That Work: The American Worker Speaks,

Salman F and Rahman M. (2008) Women Entrepreneurship and Women Enterprise Management in Karachi, Journal of Independent Studies and Research, Volume 6, Number 2, pp 21-26

Yukl, G. A. (2002) Leadership in Organizations. Prentice-Hall, New York.

http://www.partnershipway.org/html/subpages/articles/management.htm (Retrieved January 2008)

http://wwww.catalystwomen.org (Retrieved March 2008)

Dr. Mustaghis-ur-Rahman is an Associate Professor in the Department of Management and Social Sciences at SZABIST - University, Karachi

Aliya Ahmed is a student of MS in the Department of Management Sciences, at SZABIST - University, Karachi 